\title{
FORMAÇÃO CONTINUADA DE PROFESSORES DE EDUCAÇÃO INFANTIL: AVALIAÇÃO DE UM PROJETO DE EXTENSÃO
}

\section{CONTINUING EUCATION OF EARLY CHILDHOOD EDUCATION TEACHERS: EVALUATION OF AN OUTREACH PROJECT}

\author{
Caroline Machado Cortelini Conceição* \\ ORCID: https://orcid.org/0000-0002-3442-3904 \\ Luiz Cesar Teixeira dos Santos** \\ ORCID: https://orcid.org/0000-0002-9181-3474 \\ Mariane Bertoncelli*** \\ ORCID: https://orcid.org/0000-0002-1252-945X \\ Roseli de Fátima Rech Pilonetto**** \\ ORCID: https://orcid.org/0000-0001-6389-1654
}

\section{Resumo}

Este trabalho apresenta uma análise do projeto de extensão de formação continuada "A primeira infância em foco: Práticas pedagógicas e institucionais de cuidado e educação da criança”, realizado em 2018, avaliando sua contribuição para os profissionais participantes e para a rede municipal de educação. O projeto destinou-se às professoras dos Centros Municipais de Educação Infantil - CMEIs - de Francisco Beltrão/PR. Contou com a participação de 378 profissionais. A metodologia de trabalho é a pesquisa/formação, que possibilita a realização de um processo formativo junto ao grupo de sujeitos através da reflexão sobre a prática pedagógica e articulação entre teoria e prática. A avaliação foi um elemento importante da proposta, realizada de forma processual no decorrer das ações, e teve em vista perceber o envolvimento dos sujeitos e oferecer subsídios para o replanejamento das ações com as crianças nas instituições de educação infantil, e, assim, no próprio trabalho docente.

Palavras-chave: Formação de professores; Formação continuada; Extensão universitária; Educação infantil.

\begin{abstract}
This paper analyzes the continuing education outreach project "Early childhood in focus: Pedagogical and institutional practices of childcare and education" carried out in 2018. The paper evaluates the contributions of the project to the professionals involved in the project and to the municipal education network. The project was offered to teachers of the Municipal Centers of Early Childhood Education - CMEIs (Portuguese acronym) in Francisco Beltrão / PR. Three hundred and eighty seven professionals participated of the project. The work methodology adopted a research/training approach that enabled a formative process with the group of participants through reflection on pedagogical practice and the articulation between theory and practice. The evaluation carried throughout the actions aimed to understand the involvement of the participants and offer subsidies for re-planning actions for children in early childhood education institutions and, consequently to the teaching, was another an important element of the proposal.
\end{abstract}

Keywords: Teacher education; Continuing education; Outreach university project; Early childhood education.

Data recebimento: $22 / 09 / 2020$

Data de aceite: $08 / 04 / / 2021$

* Professora da Universidade Estadual do Oeste do Paraná (UNIOESTE), Francisco Beltrão - Paraná, Brasil. E-mail: cmcortelini@yahoo.com.br

** Professor da Universidade Estadual do Oeste do Paraná (UNIOESTE), Francisco Beltrão - Paraná, Brasil. E-mail: luizcts@gmail.com

*** Professora da Rede Municipal de Francisco Beltrão, Francisco Beltrão - PR, Brasil. E-mail: marianebertonceli@gmail.com

**** Professora da Universidade Estadual do Oeste do Paraná (UNIOESTE), Francisco Beltrão - PR, Brasil. E-mail: roselipilonetto@hotmail.com 


\section{Introdução}

A interação entre o ensino superior e a educação básica tem sido reconhecida como um elemento importante para a qualificação tanto da formação de professores quanto para as práticas educacionais desenvolvidas nas escolas, e a extensão universitária é uma das vias de aproximação e promoção do trabalho colaborativo entre universidade e comunidade, propiciando "[...] a interação transformadora entre Universidade e outros setores da sociedade" (FORPROEX, 2012, p. 28).

A formação de professores é uma linha de extensão que tem como propósito a "formação e valorização de professores, envolvendo a discussão de fundamentos e estratégias para a organização do trabalho pedagógico, tendo em vista o aprimoramento profissional, a valorização [...]” (FORPROEX, 2007, p. 30). A formação continuada é um direito inerente à profissão docente, está prevista no conjunto de ordenamento legal da educação, sendo compreendida como um elemento importante para a constituição e consolidação da identidade profissional.

Nessa relação, cada uma tem um papel importante a desempenhar, em que a produção de conhecimento ocorre a partir da articulação entre as duas instâncias. A escola, portanto, é mais que "[...] um campo de aplicação prática de conhecimentos ou de desenvolvimento de estratégias profissionais" (TAUCHEN; DEVECHI; TREVISAN, 2014, p. 389). Universidade e escola são lugares potencializadores do desenvolvimento profissional docente.

Neste texto analisamos, a partir de avaliações realizadas pelos sujeitos participantes, as contribuições de um projeto de extensão de formação continuada para o desenvolvimento profissional das professoras ${ }^{i}$ e diretoras da educação infantil da rede pública de educação de Francisco Beltrão/PR. O projeto de formação foi realizado em parceria com a Secretaria Municipal de Educação e Cultura de Francisco Beltrão - SMEC, com a finalidade de contribuir com a formação continuada das professoras dos Centros Municipais de Educação Infantil - CMEIs.

O objetivo central do projeto de formação continuada foi contribuir com o desenvolvimento profissional das professoras e diretoras dos Centros Municipais de Educação Infantil de Francisco Beltrão, proporcionando um processo de reflexão sobre as práticas pedagógicas e institucionais de cuidado e educação da criança pequena. Propomo-nos, nessa ação extensionista, a estabelecer um processo conjunto de reflexão sobre a prática profissional e a produção de conhecimento, através de uma dinâmica de trabalho formativa e autoformativa, possibilitando rever e repensar concepções sobre docência, primeira infância, educação infantil, bem como subsidiar a qualificação da prática pedagógica das profissionais envolvidas.

O projeto de extensão vinculou-se a um projeto de pesquisa que refletiu sobre as concepções e práticas de cuidado, educação, infância/criança, brincar e docência das/os professoras/es dos Centros Municipais de Educação Infantil de Francisco Beltrão, no intuito de problematizar tais concepções e obter subsídios para refletir sobre as necessidades das crianças. 
A docência, na educação infantil, é um campo profissional que vem se construindo. As mudanças legais das últimas décadas que estabelecem a educação infantil como primeira etapa da educação básica, o reconhecimento político da função de professor de educação infantil, bem como o reconhecimento das especificidades da educação infantil a partir das singularidades de bebês e crianças pequenas e da função social conferida a esta etapa educacional, repercutem no "surgimento" da professora de educação infantil (BUSS-SIMÃO; ROCHA, 2018; SCHMITT, 2014).

Nesse sentido, o projeto de formação continuada significou um espaço para as professoras e diretoras participantes da universidade e da escola refletirem sobre as práticas pedagógicas na educação infantil e a formação profissional inicial e continuada para esta etapa educacional, possibilitando desenvolver e analisar estratégias formativas que articulem a teoria e a prática na formação de professores.

O presente texto tem como propósito discutir e avaliar o impacto dessa proposta de formação de professores. Para tanto, apresentamos e discutimos dados obtidos através de avaliações da atividade realizada em 2018 (questionário individual de avaliação final do projeto de formação e avaliações por CMEI durante o processo, realizadas coletivamente pelas professoras de cada instituição). A avaliação foi um elemento importante da proposta e teve em vista perceber o envolvimento das participantes e auxiliar no replanejamento das ações.

\section{Delineamento metodológico do projeto de formação continuada}

O projeto de formação continuada de professoras e diretoras dos Centros Municipais de Educação Infantil - CMEI de Francisco Beltrão/PR iniciou em fevereiro de 2018 e está na sua terceira edição. O projeto abrangeu 378 participantes das 19 instituições que compõem a rede de ensino ${ }^{\text {ii }}$ em seu primeiro ano de realização. Tem como objetivo contribuir com o desenvolvimento profissional dos sujeitos participantes, ao propor a reflexão sobre as práticas pedagógicas e institucionais de cuidado e educação da criança pequena, refletindo sobre a prática pedagógica com as crianças e a gestão das instituições de educação infantil.

A metodologia de trabalho adotada foi a pesquisa/formação, opção que possibilita a realização de um processo formativo junto ao grupo de sujeitos através da reflexão sobre a prática pedagógica e articulação entre teoria e prática (GOMES, 2009). A formação foi organizada em quatro eixos temáticos que abrangem elementos centrais da prática pedagógica em instituições de educação infantil. São eles: 1) a formação de professores e a identidade profissional; 2) a indissociabilidade entre cuidado e educação; 3 ) infância e a criança como produtora de cultura; e 4) o brincar como direito da criança.

A formação estabeleceu um processo de reflexão em torno dos eixos temáticos, incluindo o diálogo sobre os temas, estudo de referenciais teóricos, observação e registro da 
prática pedagógica, propostas práticas (elaboração e desenvolvimento de planejamentos, planos de ação de gestão), análise das atividades realizadas durante os encontros de formação e a produção de Memoriais de Formação. As professoras participantes também responderam a um questionário para levantamento de dados sobre o panorama da educação infantil (dos Centros Municipais de Educação Infantil), referente à formação profissional, concepções e práticas institucionais, que ofereceu elementos para a contextualização e problematização dos temas abordados e tem sido utilizada pela equipe da universidade, juntamente com os Memoriais de Formação, para estudo sobre a realidade da educação infantil no município de Francisco Beltrão/PR.

O processo formativo, composto pelos encontros de formação, consiste na reflexão/ problematização/discussão sobre o tema coordenado pela equipe do projeto, e as atividades complementares a serem desenvolvidas pelas professoras e diretoras, individualmente ou em grupos (nos CMEIs), foram: leitura de bibliografias sobre os eixos temáticos; atividades de reflexão/ação/reflexão envolvendo a prática pedagógica; produção de memoriais e avaliação e encaminhamentos ao final de cada encontro.

Através da pesquisa/formação, é possível a constituição de comunidades de aprendizagem envolvendo o grupo de professores participantes em um processo de formação e autoformação, em uma proposta em que a observação, escuta, registro e reflexão das/sobre as ações e interações no cotidiano da instituição educacional se destacam. A partir do exercício de olhar a fundo o cotidiano, o registro possibilita o conhecimento sobre as crianças e orienta um processo de formação e autoformação (OSTETTO, 2009; GOMES, 2009). A proposta de produção dos Memoriais de Formação, como um recurso metodológico para o estabelecimento de um processo de formação e autoformação, envolve a reflexão sobre a constituição profissional e as práticas pedagógicas (SOUZA, 2003). Assim, almejamos como propósito da formação, conforme explicita Nóvoa (1997), estabelecer um trabalho de reflexividade crítica sobre as práticas e de reconstrução permanente de uma identidade pessoal.

A avaliação, para fins de acompanhamento e análise do processo, é parte inerente à proposta formativa desenvolvida e perpassou todo o percurso formativo no projeto de extensão. Teve em vista perceber o envolvimento das participantes e auxiliar no replanejamento das ações, fornecendo elementos para avaliar o impacto da proposta de formação para a rede municipal. Ao final de cada encontro temático, foi realizada uma avaliação escrita por CMEI. Desse modo, cada instituição realizava um momento de avaliação/reflexão coletiva da atividade de formação continuada, sistematizado por escrito e, posteriormente, entregue à equipe do projeto. De forma complementar, ao início de cada novo encontro com as diretoras, havia um momento destinado à socialização das avaliações/reflexões realizadas pelas instituições. Ao final do projeto, todas as professoras participantes foram convidadas a preencher um questionário individual de avaliação final do projeto de formação. Para tanto, apresentamos e discutimos, neste texto, dados obtidos através de avaliações da atividade realizada em 2018 (questionário individual de avaliação final 
do projeto de formação e avaliações por CMEI durante o processo, realizadas coletivamente pelas professoras de cada instituição).

As professoras participantes do projeto de formação preencheram termo de consentimento, livre e esclarecido, concordando com a utilização e divulgação dos dados para fins científicos. A equipe do projeto comprometeu-se em utilizar os dados para as análises e produções referentes à pesquisa e extensão sem a divulgação dos nomes dos participantes.

No ano de 2018, o qual foi analisado nesta escrita, as atividades foram programadas conforme calendário letivo das instituições de educação infantil. Foram realizados 2 encontros gerais - Seminários de Formação - com todos os participantes do projeto de formação (com duração de 8 horas cada); 2 encontros com as professoras, divididas em grupos por turmas - Berçário, Maternal I, Maternal II e Pré I -, buscando atender as particularidades de cada grupo etário (com duração de 4 horas com cada grupo); encontros bimestrais com as diretoras para tratar sobre as especificidades da gestão e fazermos a avaliação do processo formativo; e ainda, reuniões bimestrais da equipe de planejamento, composta por professoras e bolsistas da Universidade e professoras da equipe pedagógica da educação infantil da SMEC.

A proposta formativa para as diretoras envolveu a elaboração de um plano de ação que atendesse uma necessidade específica do CMEI, apoio às professoras para a elaboração dos memoriais de formação e organização de um portfólio para reunir as produções do conjunto profissional de cada CMEI. A proposta dos encontros de formação com as diretoras foi colocar em discussão a gestão na educação, refletindo sobre suas atribuições e pensando as possibilidades de atuação nos CMEIs, nos quatro eixos que compõem o processo formativo do projeto proposto. Em cada um dos encontros, a partir dos dados levantados e reflexões pontuadas pelas professoras, foi possível ampliar a compreensão sobre os eixos formativos e realizar a proposição conjunta de alternativas para as problemáticas da rede, bem como aquelas pontuais dos CMEIs.

A análise dos dados foi efetuada através da metodologia de análise documental, pautando-se pela compreensão de que a pesquisa documental permite a investigação de determinada problemática de forma indireta, por meio do estudo dos documentos que revelam modo de ser, viver e compreender um fato social dos sujeitos (BRAVO, 1991). A análise documental envolve a definição das categorias de codificação que são definidas a partir das questões da pesquisa e pela identificação das repetições ou destaques que surgem no processo de leitura e sistematização inicial dos dados (BOGDAN; BIKLEN, 1994). 


\section{A formação continuada de professores de educação infantil}

O desenvolvimento profissional docente, conforme acentua Pachane (2006, p.103), é "um contínuo", em que os professores são compreendidos como "[...] sujeitos em evolução e desenvolvimento constante". Portanto, pensar a profissionalização envolve a reflexão constante sobre a identidade profissional, as práticas pedagógicas, os contextos de atuação profissional, as condições de trabalho, dentre outros elementos constituintes da educação (OLIVEIRA et al., 2006).

Pachane (2006, p.126) pontua que a formação do professor "[...] não pode se resumir ao conhecimento aprofundado do conteúdo, nem mesmo ao domínio de algumas poucas técnicas didáticas". Nunes (2001, p.30) salienta a importância de considerar o professor em sua própria formação, "[...] num processo de auto-formação, de reelaboração dos saberes iniciais em confronto com sua prática vivenciada. Assim seus saberes vão-se constituindo a partir de uma reflexão na e sobre a prática". Nessa perspectiva, Moss (2002, p.246) defende que o profissional da educação infantil precisa ser pensado como aquele que "reflete sobre sua prática, um pesquisador, um co-construtor do conhecimento", que questiona "constantemente suas próprias imagens de criança e seu entendimento de aprendizagem infantil e outras atividades, apoiando a aprendizagem de cada criança, mas também aprendendo com ela".

Compreendemos que esse processo não acontece de forma solitária, e sim em contextos de interação, trocas de experiências e aprendizagem entre professoras, assim como nas relações destas com os seus vários contextos de vida. Azevedo (2013, p.82) assinala que a integração entre cuidado e educação deveria fundamentar a formação de seus professores, "concebendo essas duas dimensões como tendo igual importância no desenvolvimento das atividades cotidianas do professor".

Além dos fundamentos e bases da educação, também fazem parte dos saberes profissionais os advindos da experiência profissional que contempla múltiplas relações, como as vivências em sala de aula, as trocas de experiências entre os pares, seja com colegas de profissão, família e as próprias crianças (TARDIF; LESSARD, 2014). Apostando na formação de professores como um processo em construção, vários pesquisadores da área da educação têm apontado a importância de considerar os saberes advindos da experiência ou da prática social dos diferentes sujeitos que compõem o processo educativo (PIMENTA, 1994). A partir dessa compreensão, a formação continuada, ou formação em serviço, ganha central importância para o desenvolvimento profissional docente.

A formação continuada também é "[...] um espaço privilegiado para reflexão, para a construção dos saberes dos professores e sua relação com a prática pedagógica" (ZAPELINE, 2009, p.170). Deve possibilitar reflexão das ações docentes, trocas entre os sujeitos, para que se construam novos conhecimentos e que estes sejam incorporados na prática.

A formação continuada não é apenas necessária como também um direito dos professores, garantida na Lei de Diretrizes e Bases da Educação (LDB, 1996), tal como estabelece o artigo 67, ao afirmar que "[...] os sistemas de ensino promoverão a valorização 
dos profissionais da educação, assegurando-lhes [...] II - aperfeiçoamento profissional continuado". Também o Plano Nacional de Educação (PNE), na meta 16, anexo à Lei n. 13.005/14, aprovada em 25 de junho de 2014 (BRASIL, 2014), prevê “[...] garantir a todos(as) os(as) profissionais da educação básica formação continuada em sua área de atuação, considerando as necessidades, demandas e contextualizações dos sistemas de ensino".

Hibernón (2010) assevera que precisamos pensar em uma formação que seja inovadora, desconstruindo o predomínio do caráter transmissor, teorias descontextualizadas, pontuando uma formação que objetive motivar os professores a participarem e que os sujeitos se compreendam como protagonistas da formação no processo. Nessa perspectiva, os processos formativos não devem ser apenas espaço de transmissão de conhecimentos e técnicas, e sim um local que possibilite ao sujeito refletir e reconhecer sua identidade profissional. Os professores devem assumir a condição de "[...] serem sujeitos da formação, compartilhando seus significados" (IMBERNÓN, 2010, p. 78). Trata-se de momento determinante de repensar a práxis pedagógica, apropriar-se de novos conhecimentos, planejar ações, bem como constitui uma ocasião de compartilhar conhecimentos e experiências.

Por fim, entendemos que a formação profissional para a educação infantil deve ser pensada como um processo organizado, contínuo, intencional e particularizado. Consideramos esta etapa educacional enquanto contexto específico, por se tratar do trabalho com crianças de 0 a 5 anos, que tem como eixo de sustentação a articulação do cuidado e da educação (OLIVEIRA et al., 2006).

\section{A avaliação do processo formativo no projeto de extensão}

A avaliação é um elemento de central importância para o processo formativo, servindo para a orientação das ações (LUCKESI, 2012) e envolve a coleta, análise e síntese dos dados. Nessa perspectiva, a avaliação permeou o processo formativo, com a finalidade de reorientar as ações e possibilitar a percepção de sua contribuição para a constituição profissional das professoras envolvidas.

Apresentaremos e discutiremos os dados referentes aos dois encontros realizados por turma de professoras, a percepção geral das diretoras e a avaliação geral final do processo formativo. Os sujeitos avaliaram de forma positiva os encontros de formação, justificando que a discussão temática é pertinente e auxilia a pensar a prática docente na educação infantil; por sua vez, algumas profissionais consideraram que sentiam necessidade de temas mais pontuais que esta proposta formativa não atenderia e propuseram o desenvolvimento de atividades práticas (propostas metodológicas) para outros momentos do projeto. A proposta de elaboração dos memoriais de formação foi o motivo de maior apreensão do grupo, tendo havido considerações positivas e negativas, em que algumas professoras destacaram que 
estavam motivadas para a escrita dos memoriais e outras apreensivas, por considerarem uma atividade difícil e de grande envolvimento.

Um elemento de destaque a ser considerado é o fato de a formação estar sob a responsabilidade da universidade. Há grandes expectativas em relação a este aspecto e consideram importante para a Rede Municipal o estabelecimento dessa parceria. Um dos CMEIs aponta como destaque a questão:

\begin{abstract}
Vimos como algo positivo a parceria realizada entre a prefeitura e a Unioeste, com professores qualificados e que possam se fazer presentes nas instituições para que assim consigam um olhar mais profundo acerca da realidade do dia a dia escolar, desse modo a universidade cumpre sua função de aliar o tripé ensino, pesquisa e extensão (CMEI 3).
\end{abstract}

A seguir, o Gráfico 1 expressa a avaliação do primeiro encontro de formação por turma, sintetiza a recorrência por CMEI dos principais tópicos assinalados pelas professoras. $\mathrm{O}$ encontro referido teve duração de 4 horas, em que as professoras estavam divididas por turma de atuação (Berçário; Maternal I e II e Pré I). Esta subdivisão é uma organização da SMEC. Nesse encontro, foram abordados dois eixos formativos: 1) a formação de professores e a identidade profissional; 2) a indissociabilidade entre cuidado e educação.

Do total de 19 CMEIs, 16 entregaram a avaliação, que foi respondida coletivamente e sistematizada pelas diretoras das instituições.

Gráfico 1 - Síntese da avaliação do encontro de formação por CMEI ( $1^{\circ}$ encontro por turmas/2018)

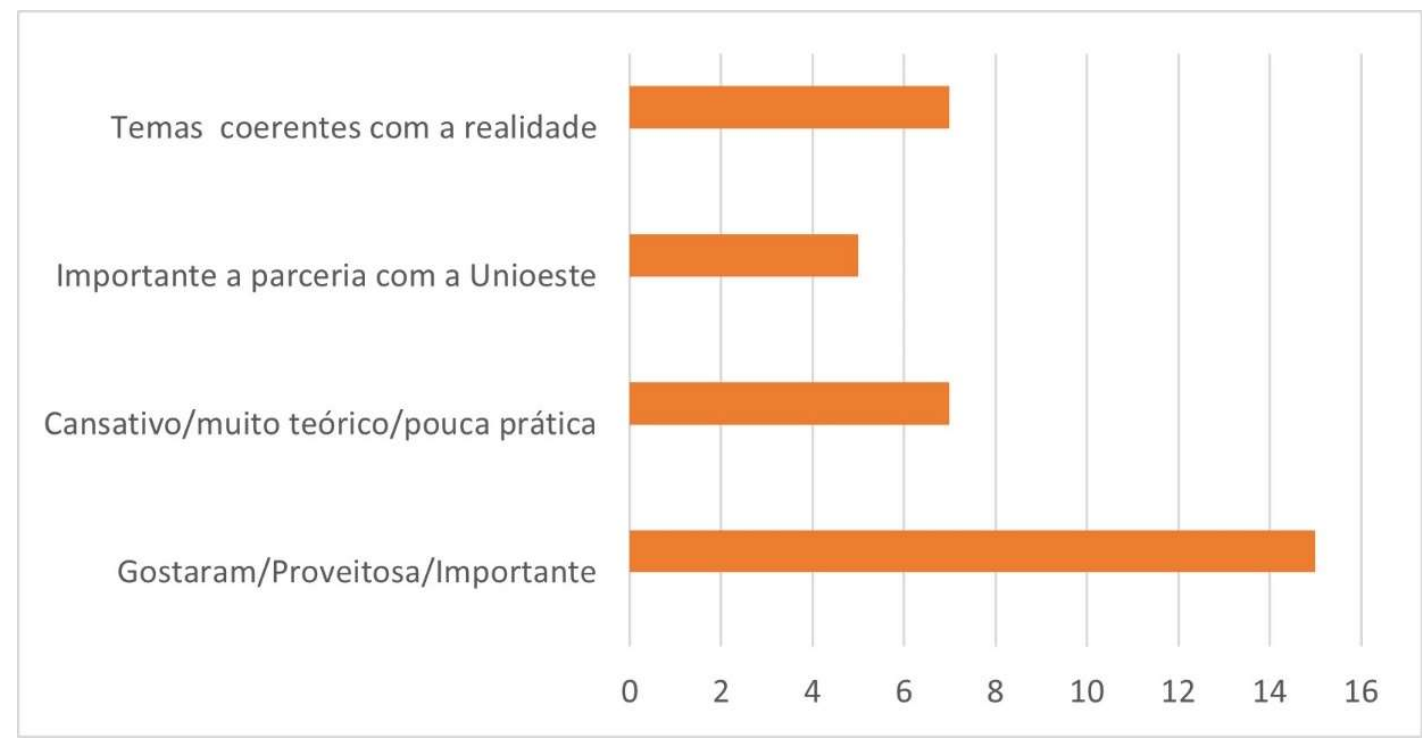

Fonte: Elaborado pelos autores, 2019. 
Um aspecto de destaque pontuado pelas professoras nas avaliações por CMEI é a importância do trabalho para o desenvolvimento pessoal e profissional:

\begin{abstract}
Acreditamos nessa proposta de formação continuada como recurso de desenvolvimento pessoal, profissional e institucional dos professores, qualificando seu trabalho, que pressupõe uma ação fundamentada na teoria e na reflexão da própria prática para transformar a realidade no qual está inserido (CMEI 19).

O objetivo é contribuir com o desenvolvimento profissional, refletindo sobre as práticas pedagógicas, dificuldades e desafios que encontramos no decorrer de nosso trabalho e da formação. Ressaltamos o quão é importante nos reportar/trabalhar temáticas que vêm de encontro com a realidade (CMEI 9).
\end{abstract}

No conjunto das avaliações recebidas, percebemos que a maioria das professoras afirma que a formação possibilitou reflexões sobre a prática e discussões em relação às dificuldades encontradas nas instituições. Consideram o encontro um momento para troca de experiências, socialização das problemáticas do cotidiano do trabalho docente e oportunidade para o surgimento de novas ideias que contribuam com o trabalho de cada uma na sua realidade específica. $\mathrm{O}$ Gráfico 2 sintetiza as contribuições elencadas pelas professoras por CMEI.

Gráfico 2 - Síntese das contribuições dos encontros de formação por CMEI ( $1^{\circ}$ encontro por turmas/2018)

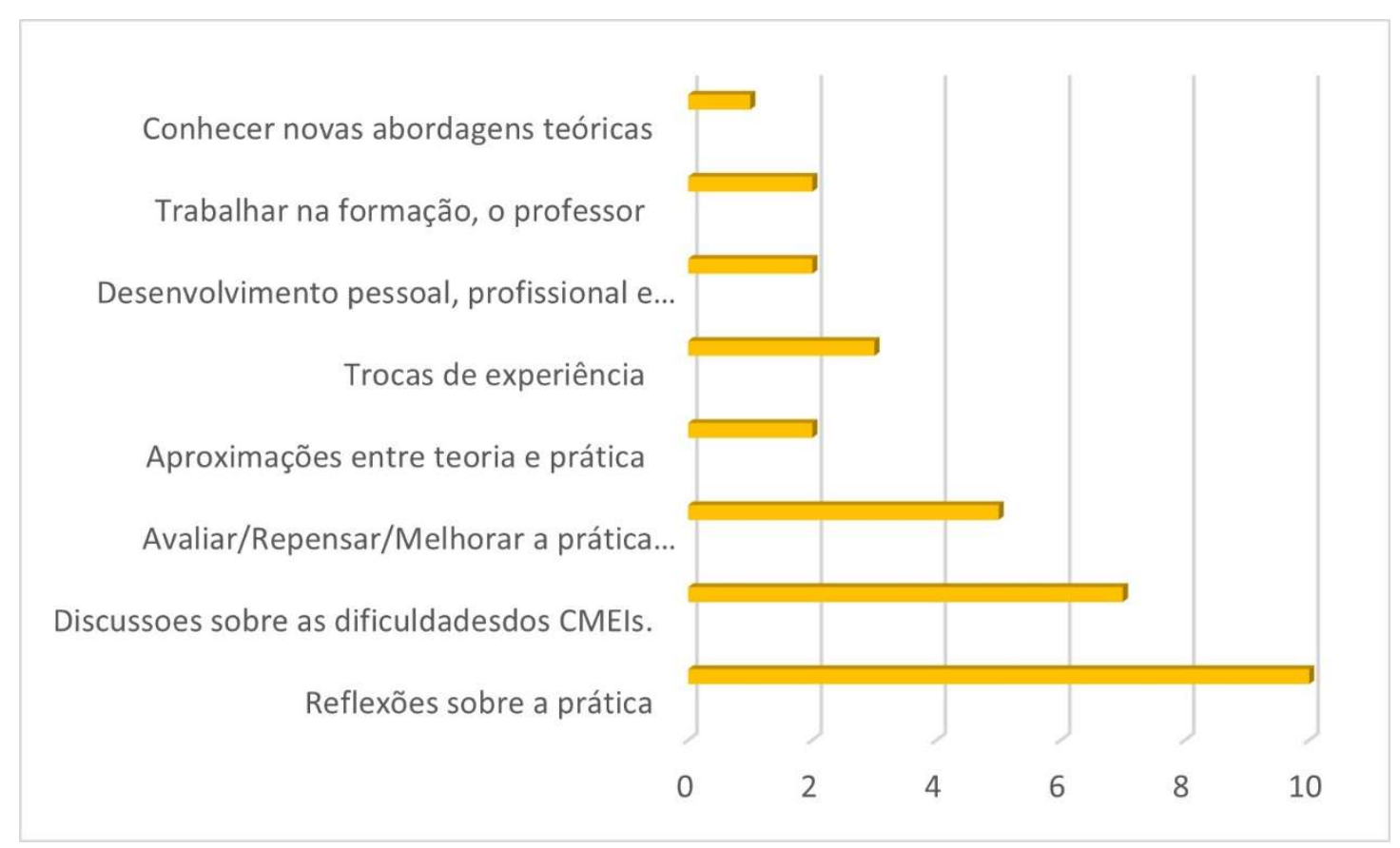

Fonte: Elaborado pelos autores, 2019. 
O destaque em relação à contribuição do projeto foi propiciar a reflexão sobre a prática, que podemos afirmar que está relacionada a outros dois elementos que surgem significativamente nas avaliações: avaliar/repensar/melhorar a prática e discussões sobre as dificuldades dos CMEIs. O processo formativo precisa, efetivamente, contribuir para "[...] pensar, analisar, questionar a sua prática a fim de agir sobre ela" e não somente reproduzir "[...] ideias e práticas que lhes são exteriores.” (SANTOS; CESTARO; LUZARDO, 2009, p.9). Nesse sentido,

A formação continuada deveria apoiar, criar e potencializar uma reflexão real dos sujeitos sobre sua prática docente nas instituições educacionais e em outras instituições, seus esquemas e funcionamento, suas atitudes, etc., estabelecendo de forma firme o processo constante de autoavaliação do que se faz e porque se faz (IMBERNÓN, 2010, p. 47).

É necessário propiciar espaços formativos que possibilitem aos professores compreender o contexto em que estão inseridos de forma articulada, pois de nada adianta uma formação baseada apenas em treinamentos e que não leve em conta as especificidades de cada escola e dos sujeitos envolvidos. Nessa perspectiva, o docente é concebido como um sujeito constituído por diferentes vivências, diferentes concepções. Nesse viés, “[...] o que a reflexão crítica propõe é a análise de forma crítica das condições sociais e históricas nas quais se formaram os modos de entender e valorizar a prática educativa, problematizando, assim, o caráter político da prática." (SANTOS; CESTARO; LUSARDO, 2009, p. 13).

A reflexão é um processo coletivo, afirma Contreras (2002). Salientamos a importância da dimensão coletiva do trabalho docente. A formação continuada é um espaço que pode ser de trocas de experiências, de participação, de conhecer outras formas de pensar. Uma das diretoras assinala que esse foi um aspecto importante do processo:

[...] a parte que mais gostaram foi o momento que se abriu para falar sobre as dificuldades encontradas no seu dia a dia, pois, no geral, não há uma preocupação em deixar colocar para fora todas as angústias e dificuldades do trabalho. Sugerem uma formação em que o público discuta mais essas dificuldades. (CMEI 8)

Outro elemento assinalado pelas professoras, o qual consideramos pertinente destacar, é a ênfase teórica do projeto. Com relação a este aspecto, algumas se posicionaram sobre a importância da teoria para a formação e outras argumentam que a formação deveria ser mais prática. Acerca dessa compreensão, destacamos duas avaliações:

Gostaríamos que tivesse menos teorias, as quais já discutimos diversas vezes. Sabemos que a teoria e a prática andam juntas, mas pedimos que as formações sejam na maior parte voltadas para a prática, estimulando e dando motivação quando voltarmos para o CMEI. (CMEI 11)

A dinâmica realizada no decorrer do curso foi um pouco exaustiva, mas não vejo outro caminho para socializar um conhecimento tão complexo em pouco tempo; 
mesmo assim, tivemos momentos de conversas para expor nossas dificuldades no trabalho. De ouvir e compreender um pouco teoricamente sobre o assunto polêmico complexo e cotidiano, que é o cuidar e o educar. (CMEI 19)

Acerca dessa questão, Tardif (2003, p. 54) esclarece que o saber docente é um “[...] saber plural, formado de diversos saberes provenientes das instituições de formação, da formação profissional, dos currículos e da prática cotidiana”. E estes saberes estão articulados à formação profissional e ao exercício da docência. Assim, ao conceber o processo educativo como a mobilização de diversos saberes, compreende-se que tanto os saberes teóricos quanto os práticos são conjuntamente mobilizados pelo professor em seu trabalho. Diante disso, compreendemos que a formação continuada precisa abranger a formação teórica, possibilitando ao professor acesso ao conhecimento, espaços de estudo e reflexão sobre temas e campos de conhecimento pertinentes à sua profissão e área específica de atuação.

O segundo encontro de formação por turmas abordou os eixos temáticos "infância e a criança produtora de cultura" e "o brincar como direito da criança". Referente a este encontro, recebemos menos avaliações por CMEI, somando um total de 13, de 19 CMEIs. O Gráfico 3 apresenta a avaliação geral referente a este encontro de formação.

Gráfico 3 - Síntese da avaliação do encontro de formação por CMEI ( $2^{\circ}$ encontro por turmas/2018)

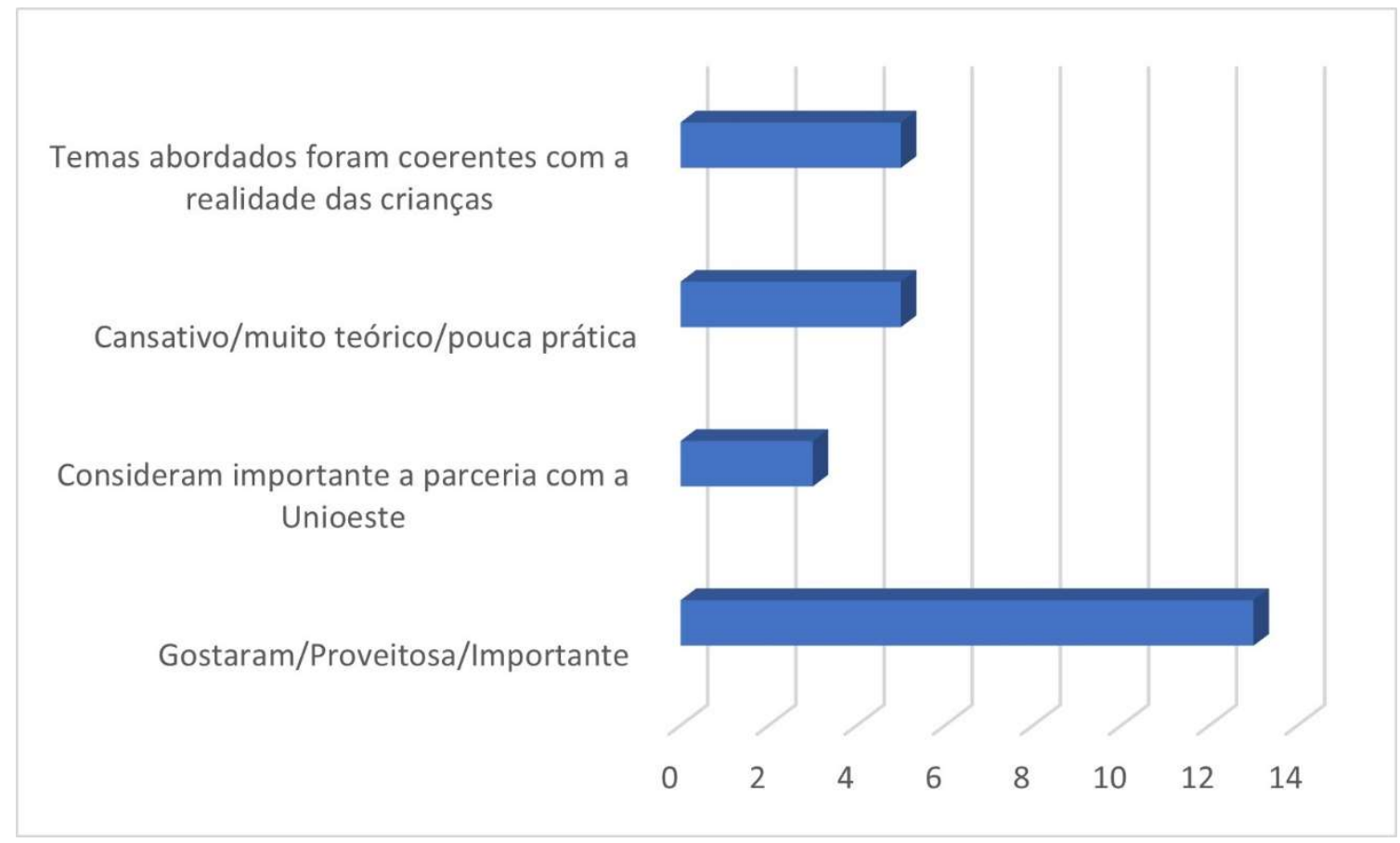

Fonte: Elaborado pelos autores, 2019. 
$\mathrm{Na}$ avaliação geral, notamos que surgem os mesmos tópicos do primeiro encontro, ao considerarem proveitosa e destacarem como importante a parceria da Universidade com a SMEC e os temas abordados como coerentes com a realidade das instituições. As professoras consideraram cansativa a abordagem teórica. Destacamos que, nesse encontro de formação, foi realizada parte prática com oficina de confecção de brinquedos, juntamente com a abordagem dialogada sobre os temas crianças, infâncias e brincadeiras, que incluiu um momento de trocas de experiências entre as professoras sobre os temas.

No que diz respeito às contribuições, houve destaque para os temas abordados, tendo sido enfatizado pelas professoras que o momento de formação proporcionou reflexões sobre as crianças e a infância, sobre as brincadeiras e ideias para o trabalho com as crianças e a importância do brincar. Novamente, foi acentuada como contribuição importante a possibilidade de reflexão sobre a prática. Assinalamos algumas avaliações que destacam esses elementos:

A formação continuada nos fez pensar como estamos observando as crianças aqui no CMEI, compreender os pontos de vista diferentes, de fazer se entender e prevenir futuros problemas de aprendizagens. (CMEI 1)

\begin{abstract}
A formação continuada nos fez pensarmos as crianças que temos em nossa sala de aula, como são suas características, como vivem, e pensando nisso nos fez refletir nossas práticas pedagógicas. $\mathrm{O}$ que podemos melhorar como professores no processo de crescimento e desenvolvimento dessas crianças. Nossa responsabilidade é muito grande, pois estamos construindo a base, o alicerce da educação e cultura das mesmas, para que possam entender o mundo que vivem com mais clareza e facilidade, e, para isso, o brincar e o brinquedo são fundamentais nesse processo de descoberta. (CMEI 5)
\end{abstract}

Gráfico 4 - Síntese das contribuições dos encontros de formação por CMEI ( $2^{\circ}$ encontro por turmas/2018)

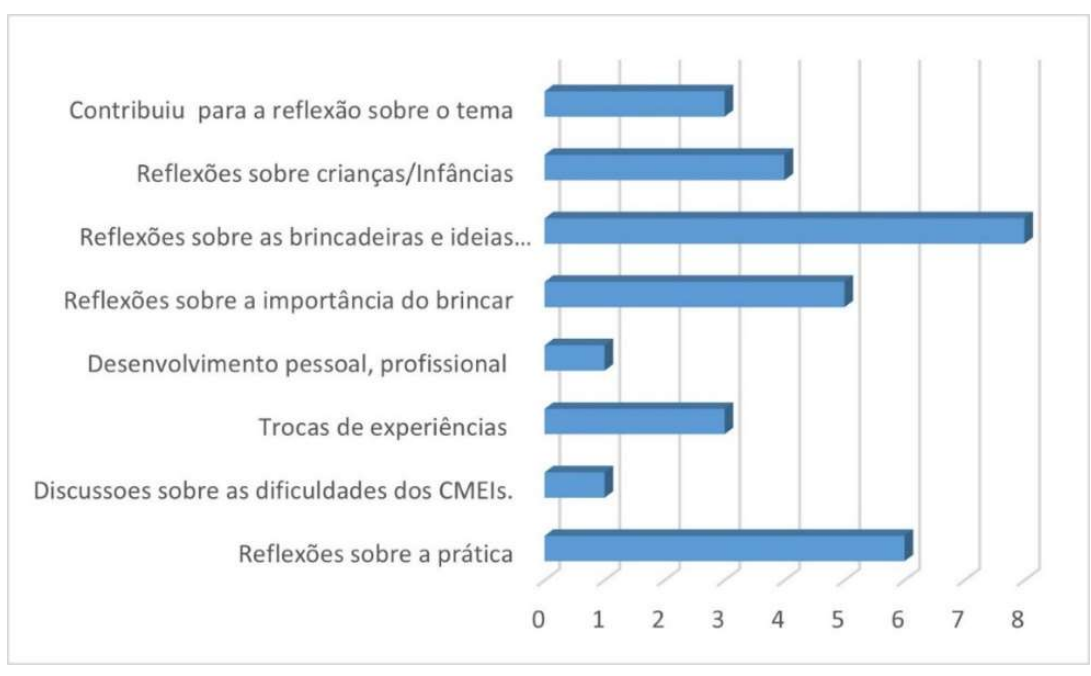

Fonte: Elaborado pelos autores, 2019. 
Explicitamos, nas considerações acima, que o tema proposto provocou um olhar mais atento em relação às crianças e, além disso, uma reflexão da prática pedagógica. Neste segundo encontro de formação, percebemos que houve mais interesse nas atividades práticas (sugestões de atividades, confecção de materiais). As atividades práticas são de extrema importância, porém, é necessário a teoria, com o intuito de propiciar reflexões sobre as práticas pedagógicas, as concepções de crianças e infâncias. Foi interessante essa dinâmica, para que as professoras refletissem sobre a importância dos conceitos teóricos para compreensão das especificidades do trabalho na Educação Infantil.

A avaliação final foi realizada por meio de questionário - formulário composto de questões objetivas - encaminhado a todas as professoras. Do total de 378 professoras, recebemos o retorno de 180 professoras, das quais 158 são favoráveis à continuidade do projeto. No geral, as professoras consideraram a formação positiva, e uma pequena parcela considera regular.

Gráfico 5 - Avaliação final geral do projeto de formação continuada (2018)

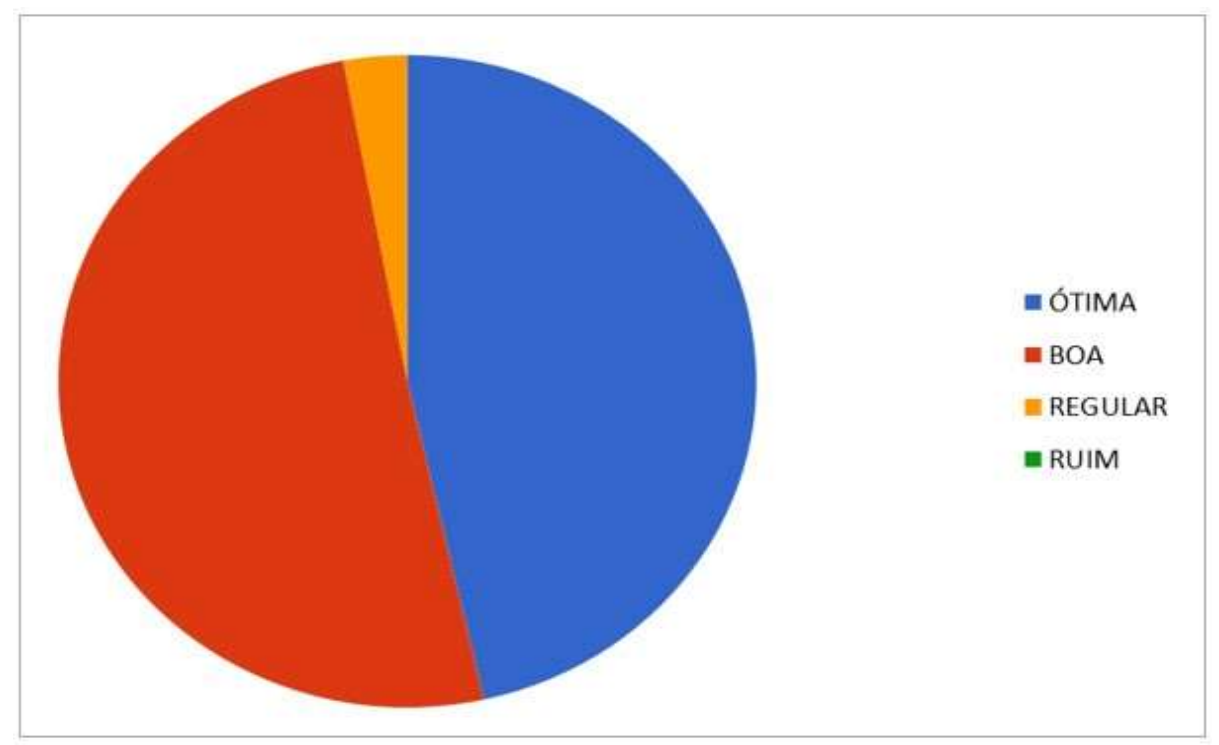

Fonte: Elaborado pelos autores, 2019.

Em relação às dificuldades, conforme aponta Gráfico 6, notamos que parcela significativa sentiu a escrita dos memoriais de formação e a leitura de textos indicados, por serem atividades que muitas vezes não são exercitadas no cotidiano pedagógico. Contudo, compreendemos que se faz necessário esse exercício de escrita e sustentação em teorias que auxiliem na reflexão da prática pedagógica. 
Gráfico 6 - Dificuldades encontradas durante a formação continuada (2018)

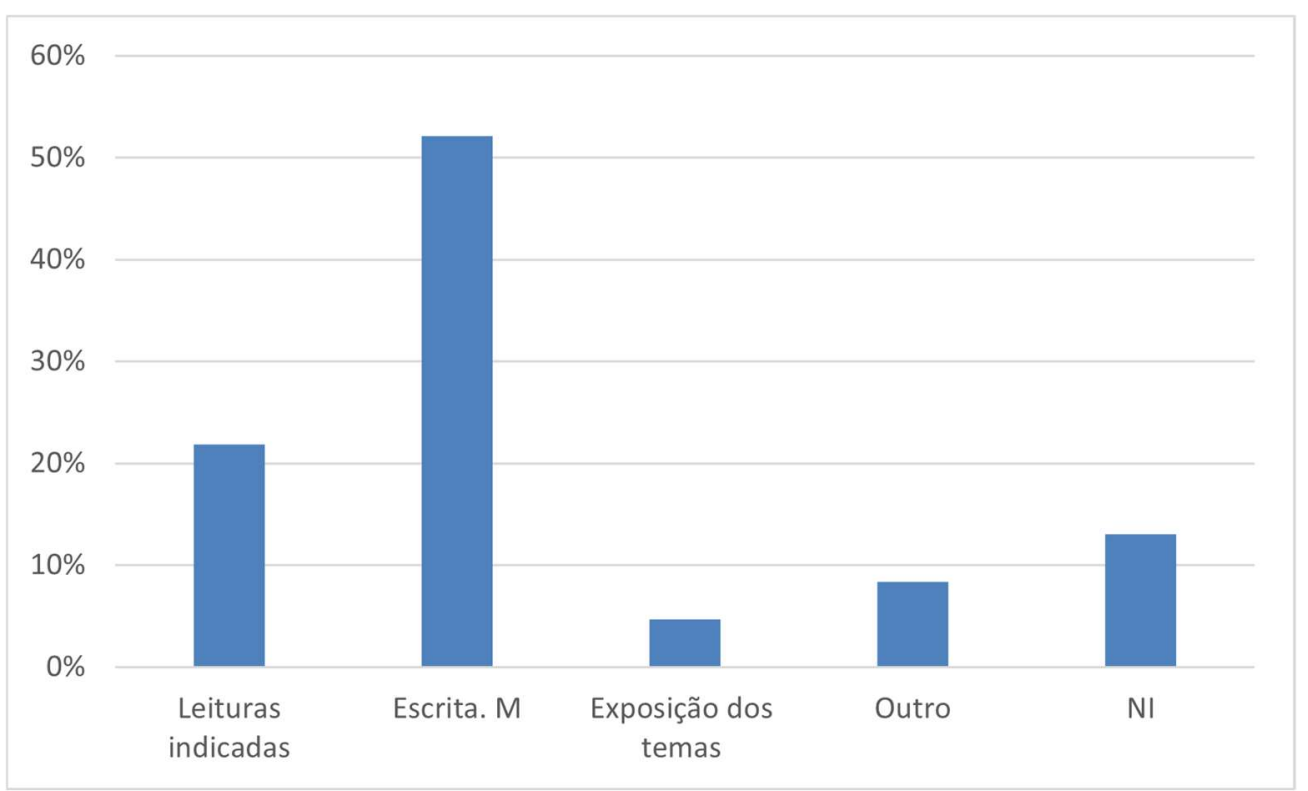

Fonte: Elaborado pelos autores, 2019.

É significativo destacar que, para 94\% das professoras, os temas foram pertinentes e importantes no processo formativo. Umas das professoras acentua: "Muito importante esse momento de formação para melhor conhecermos as crianças e nos questionarmos no que podemos melhorar enquanto professor." (PROFESSOR F).

O processo de formação continuada mobilizou reflexões sobre as concepções das participantes no que tange ao cuidado, educação, formação profissional, criança, infância, brincar, função da instituição de educação infantil, bem como problematizou as práticas com as crianças e as relações profissionais na educação infantil.

Dessa maneira, a relação teórico-prática do trabalho docente perpassa a formação realizada em 2018, com destaque para a necessidade de estudo sobre os temas inerentes à educação infantil, além da importância da universidade se fazer presente na formação continuada de professores, haja vista que possibilita a aproximação desses dois espaços que, mutuamente, contribuem para a educação. 


\section{Considerações finais}

O percurso formativo desenvolvido no ano de 2018 proporcionou o envolvimento dos participantes, o estabelecimento de um processo reflexivo sobre os saberes e fazeres no campo da educação infantil, pautado por referenciais teóricos e, especialmente, o estreitamento da relação universidade e escola.

A equipe formadora possui proximidade e familiaridade em relação ao contexto em que foi desenvolvida a proposta, pois, como docentes do curso de Pedagogia, realizamos outros projetos de extensão e pesquisa no contexto, acompanhamos os estágios supervisionados na educação infantil, vários egressos do curso compõem o conjunto de professoras de educação infantil. Consideramos que este foi um fator que possibilitou ajustarmos a abordagem em conformidade com as necessidades do contexto. Outro elemento importante do processo formativo que destacamos é a realização do planejamento conjunto com a equipe da SMEC, bem como as reuniões de caráter formativo, avaliativo e de replanejamento realizadas com as direções dos CMEIs.

No que concerne aos elementos pontuados, Romanowski (2006, p. 41) alerta que:

Para o sucesso de um programa de formação continuada, é importante a realização de diagnóstico das necessidades formativas dos professores, ou seja, um dos princípios dos programas de formação consiste em fornecer respostas para as necessidades de desenvolvimento profissional indicadas pelos professores.

O processo efetuado por este projeto de formação continuada teve essa característica, distanciando-se dos pacotes prontos de formação, por diversas vezes utilizados como a solução para as redes de ensino cumprirem a exigência da lei. Compreendemos que a formação continuada precisa constituir um espaço que possibilite ao professor trocas de experiências, de ideias e reflexão crítica, a partir da realidade experienciada pelas professoras e gestoras das instituições de educação infantil.

\section{Referências}

AZEVEDO, H. H. O. Educação Infantil e formação de professores: para além da separação cuidar-educar. São Paulo: Unesp, 2013.

BOGDAN, R. C.; BIKLEN, S. K. Investigação qualitativa em educação. Tradução Maria João Alvarez, Sara Bahia dos Santos e Telmo Mourinho Baptista. Porto: Porto Editora, 1994. 
BRASIL. Lei n ${ }^{\circ}$ 9.394/96, de 23 de dezembro de 1996. Estabelece as diretrizes e bases da educação nacional. Diário Oficial da República Federativa do Brasil, Brasília, DF, 23 dez. 1996. Disponível em: <http://www.planalto.gov.br/ccivil_03/Leis/L9394.htm>. Acesso em: 24 nov. 2015.

BRASIL. Lei Federal 13.005, de 25 de junho de 2014. Aprova o Plano Nacional de Educação - PNE e dá outras providências. Brasília, DF, 25. jun. 2014. Disponível em: $<$ http://www.planalto.gov.br/ccivil_03/_ato2011-2014/2014/lei/113005.htm>. Acesso em: 17 ago. 2016.

BRAVO, R. S. Técnicas de investigação social: Teoria e ejercicios. 7. ed. rev. Madrid: Paraninfo, 1991.

BUSS-SIMAO, M.; ROCHA, E. A. C. Docência na educação infantil: uma análise das redes municipais no contexto catarinense. Rev. Bras. Educ., Rio de Janeiro, v.23, e.230021, 2018. Disponível em: $<$ http://www.scielo.br/scielo.php?script=sci_arttext\&pid=S141324782018000100216\&lng=pt\&nrm=iso $>$. Acesso em: 17 fev. 2020. Epub05-Abr-2018. https://doi.org/10.1590/s1413-24782018230021.

CONTRERAS, J. Autonomia de professores. São Paulo: Cortez, 2002.

HIBERNÓN, F. Formação continuada de professores. Porto Alegre: Artmed, 2010.

FORPROEX. Fórum de Pró-Reitores das Instituições Públicas de Educação Superior Brasileiras. Política Nacional de Extensão Universitária. Manaus: FORPROEX, 2012.

FORPROEX. Fórum de Pró-Reitores das Instituições Públicas de Educação Superior Brasileiras. Extensão universitária: organização e sistematização. Belo Horizonte: FORPROEX, 2007.

GOMES, M. O. Formação de professores na educação infantil. São Paulo: Cortez, 2009.

LUCKESI, C. C. Avaliação da Aprendizagem na escola. In: LIBÂNEO, J. C.; ALVES, N. (org.). Temas de pedagogia: diálogos entre didática e currículo. São Paulo: Cortez, 2012. p. 433-451.

MOSS, P. Reconceitualizando a infância: crianças, instituições e profissionais. In:

MACHADO, M. L. A. (org.). Encontro e desencontros em educação infantil. São Paulo: Cortez, 2002. p. 235-248.

NÓVOA, A. Formação de professores e profisssão docente. In: NÓVOA, A. (coord.). Os professores e a sua formação. 3. ed. Porto: Publicações Dom Quixote, 1997. 
NUNES, C. M. F. Saberes docentes e formação de professores: um breve panorama da pesquisa brasileira. Revista Educação \& Sociedade, ano XXII, n. 74, abr. 2001.

OLIVEIRA, Z. M. R. et al. Construção da identidade docente: relatos de educadores de educação Infantil. Cadernos de pesquisa, São Paulo, v. 36, n. 129, p. 547-571, set./dez.

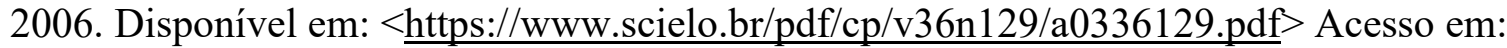
24 mar. 2018.

OSTETTO, L. E. Observação, registro, documentação: nomear e significar as experiências. In: OSTETTO L. E. (org.). Educação Infantil: saberes e fazeres da formação de professores. São Paulo: Papirus, 2009.

PACHANE, C. G. Teoria e prática na formação de professores universitários: elementos para discussão. In: RISTOFF, D.; SEVEGNANI, P. (org.). Docência na educação superior: Brasília: Instituto Nacional de Estudos e Pesquisas Educacionais Anísio Teixeira, 2006. p. 97-146.

PIMENTA, S. G. Estágio na formação de professores: unidade entre teoria e prática? São Paulo: Cortez, 1994. 224 p.

ROMANOWSKI, J.P. Formação e profissionalização docente. Curitiba: IBPEX, 2006.

SANTOS, A.; CESTARO, I. S.; LUSARDO, R. C. C. Professor reflexivo: Gênese e implicações atuais. In: SIMPÓSIO ESPAÇO E EDUCAÇÃO, 1., Juiz de Fora, 2009. Anais... Juiz de Fora/MG, 2009. Disponível em:

$<$ http://seer.uftm.edu.br/revistaeletronica/index.php/revistatriangulo/article/view/2607/pdf $>$ Acesso em: 24 mar. 2018.

SCHMITT, R. V. As relações sociais entre professoras, bebês e crianças pequenas:

contornos da ação docente. Tese (Doutorado em Educação) - Universidade Federal de Santa Catarina - UFSC, Florianópolis, 2014.

SOUSA, J. V. Narrativas de professores e identidade docente: Educação, São Paulo, v. 16, p.11-24, 2003. Disponível em: $<$ https:// revistas.pucsp.br/index.php/psicoeduca/article/view/31358>. Acesso em: 13 jan. 2018. 
TARDIF, M.; LESSARD, C. Trabalho docente: elementos para uma teoria da docência como profissão de interações humanas. 9. ed. Petrópolis, RJ: Vozes, 2014. 317 p.

TAUCHEN, G.; DEVECHI C. P. V.; TREVISAN, A. L. Interação Universidade e Escola: uma colaboração entre ações e discursos. Diálogo Educ., Curitiba, v. 14, n. 42, p. 369-393, maio/ago. 2014. Doi: http://dx.doi.org/10.7213/dialogo.educ.14.042.DS03. Acesso em: 24 mar. 2018.

ZAPELINE, C. A. Processos formativos constituídos no interior das instituições de Educação Infantil: uma experiência de formação continuada. Pro-Posições, Campinas, v. 20. p. 164-184. Disponível em: $<$ http://www.scielo.br/pdf/pp/v20n2/v20n2a11.pdf $>$ Acesso em: 10 out. 2018.

\footnotetext{
Notas

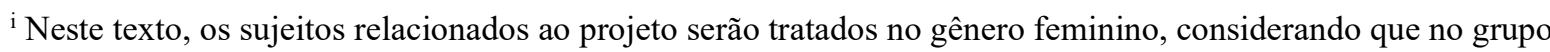
envolvido há predominância de mulheres.

ii Atualmente, são 460 professoras (entre efetivas, PSS e contratos de estágio) atuando em 20 Centros Municipais de Educação Infantil.
} 